Article

\title{
Effect of Sky Discretization for Shading Device Calculation on Building Energy Performance Simulations
}

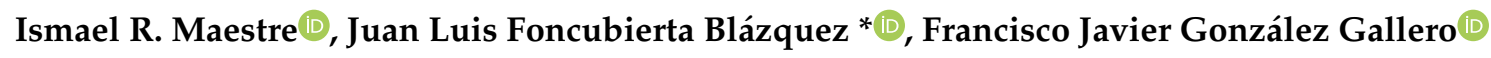 \\ and J. Daniel Mena Baladés
}

Escuela Politécnica Superior de Algeciras, University of Cadiz, 11202 Cadiz, Spain; ismael.rodriguez@uca.es (I.R.M.); javier.gallero@uca.es (F.J.G.G.); jesusdaniel.mena@uca.es (J.D.M.B.)

* Correspondence: juanluis.foncubierta@uca.es; Tel.: +34-956-028000

Received: 5 February 2020; Accepted: 13 March 2020; Published: 16 March 2020

check for updates

\begin{abstract}
The calculation of sunlit surfaces in a building has always been a relevant aspect in building energy simulation programs. Due to the high computational cost, some programs use algorithms for shading calculation for certain solar positions after discretization of hemispherical sky. The influence of the level of discretization on the estimation of incident direct radiation on building surfaces, as well as on the required computational times, are studied in this work. The direct solar energy on a window for a year, with simulation time steps of five minutes, has been simulated by using an algorithm based on Projection and Clipping Methods. A total of 6144 simulations have been carried out, varying window sizes, window orientations, typologies of shading devices, latitudes and discretization levels of the hemispherical sky. In terms of annual incident solar energy, the results show that maximum error values are about $5 \%$ for a low level of angular discretization. Errors up to $22 \%$ in hourly incident solar energy have been estimated for some of the configurations analysed. Furthermore, a great number of configurations show errors of shading factor on a window of up to $30 \%$, which could be most relevant in studies of natural lighting. The study also shows that the improvement achieved by the most accurate discretization level implies an increase in computational cost of about 30 times.
\end{abstract}

Keywords: shading calculations; sky discretization; building energy simulation

\section{Introduction}

The relevance of solar radiation on the energy consumption and natural lighting levels of a building is well-known [1]. The scientific literature about the energy impact of shading devices [2] on buildings is quite large. Although it not the aim of the present work, by way of illustration, the studies by Tzempelikos et al. [3,4] and Mettanant et al. [5] can be highlighted. They show that suitable control strategies on shading elements in buildings (overhangs, louvers, blinds, etc.) lead to energy savings greater than $75 \%$ in lightning and $20 \%$ in air conditioning, respectively. Furthermore, a cooling potential of up to $8.5^{\circ} \mathrm{C}$ has been estimated by using appropriate shading methods in arid climates [6]. In addition to energy savings, some authors have also focused their attention on the improvement in comfort conditions. Thus, Choi et al. [7] quantified parameters such as the productivity, concentration and relaxation levels of the occupants in offices with dynamic shading devices, reporting an increase in the so-called "positive emotional responses" of $26 \%$.

Shin et al. [8] state that Building Energy Performance Simulation (BEPS) programs are widely used as a support for building design and systems. Crawly et al. [9] provide a comprehensive review of the most relevant BEPS programs, in which EnergyPlus [10], DOE2 [11] and TRNSYS [12] could be highlighted for their recognized standing. EnergyPlus, which has been developed in collaboration with 
the National Renewable Energy Laboratory (NREL) from the United States, is based on the building energy balance with adjustable time steps. DOE2, financed by the Energy Department of the US, uses the well-known transfer functions for the calculation of thermal loads within one-hour time steps. Finally, TRNSYS is a general-purpose application software developed by the Solar Energy Laboratory at the University of Wisconsin-Madison, for the transient simulation of thermal systems with a module called TrnBuild for building thermal simulations.

Building energy performance simulation (BEPS) programs include algorithms to calculate sunlit surfaces from the geometric pattern of the building and its shading elements. Kirimtat et al. [1] undertake an interesting review in which, from the works published from 1996 to 2015, different existing methodologies of shading calculation are analysed. The methodologies used in BEPS could be classified into two groups [13]: on the one hand, those known as ray tracing methods, which consist in generating a finite number of rays from the light source to the surface and, on the other hand, those based on the projection of polygons in the path of a solar ray and their subsequent intersection or clipping, called Projection and Clipping Methods (P\&C Methods). Recently, De Almeida et al. [14] have used a pixel-counting method as an additional method within BEPS, achieving an improvement of up to ten times in computing time compared with P\&C methods, although it has not been extended to the main BEPS programs.

BEPS programs usually develop annual simulations with hourly time steps or smaller, conducting shading calculations for each single time step. Traditionally, due to the high computational cost of this demanding process, BEPS programs often use an approximation in which shading calculations are made for one representative day of the month (DPM Methods). The study carried out by Maestre et al. [15] shows that DPM methods obtain errors of up to $26 \%$ in the estimation of incident total solar radiation for different geometric configurations of overhangs and sidefins. EnergyPlus [10] allows the user to adjust both the period ( 20 days by default) and the time-step ( $15 \mathrm{~min}$ by default).

Jones, Greenberg and Pratt [16], in a study of the advantages of computer graphics rendering methods compared with analytical methods, show errors on incident beam radiation and the corresponding computing time when the frequency of the representative days $(7,14$ and 28 days) and the angle of discretization are changed. Error values of $5 \%$ (for 7 days and $1^{\circ}$ ) and $55 \%$ (for 28 days and $20^{\circ}$ ) were found.

An option to avoid the former DPM approximation and to have shading calculations for every time step of an annual simulation is to calculate beforehand (precalculate) and store shading surfaces for a set of specific sun positions. The methods based on this precalculation process are called Hemispherical Sky Discretization (HSD) Methods. They are predicated on the repetition of solar positions throughout the year, which allows the reduction in the number of calculations needed.

The accuracy of HSD methods obviously depends on the number of positions selected to do shading calculations. Thus, Cheung and Chung [17] apply an angular discretization of the hemispherical sky with $5^{\circ}$ azimuth and altitude divisions, for the calculation of the probable sunlight duration used by British Standards [18]. This calculation can be accelerated with some preprocessing of the feasible solar positions. In this sense, Sánchez de la Flor et al. [19] propose the use of a non-dimensional altitude and azimuth, which assures the calculation in the former positions.

Some BEPS already incorporate these methods in order to reduce the computing time. For instance, TRNSYS [12] uses an HSD method based on a Tregenza discretization [20] with the improvement proposed by Bourgeois [21], in which a scaling factor is used to increase the number of direct solar positions, achieving a higher resolution. DOE-2 applies this technique only for the calculations of natural lighting, using twenty preset positions [22].

There is a great number of studies related to shading calculation in buildings that can be found in the scientific literature about the influence of typology and control of shading elements, comparison of different methods, etc. However, none of the consulted works show a clear relationship between the degree of accuracy achieved in shading calculations and computational cost when HSD methods are applied in the energy simulation of buildings. 
The present work focuses on the influence of discretization used in HSD methods applied to beam radiation calculation on shading devices. This influence has not been studied yet, despite the fact that these methods are currently used by the most common BEPS programs. The study assesses the error made in the estimation of direct solar radiation on external building surfaces due to the uncertainty in the so-called shading factor and the computational effort associated with the shading calculation process.

First of all, the developed study cases are defined, as well as different indicators used to measure the accuracy and computational cost of each discretization. Then, a deep analysis of the influence of the discretization of hemispherical sky on incident radiation and computing times based on latitude, the typology of shading devices and orientation is carried out. Finally, the main conclusions of the present study are drawn.

\section{Methodology}

\subsection{Study Cases}

Study cases have been selected in order to cover the usual configurations of shading devices in buildings (Figure 1), such as windows with overhangs or sidefins, whose shading patterns have a significant impact on incoming solar energy.

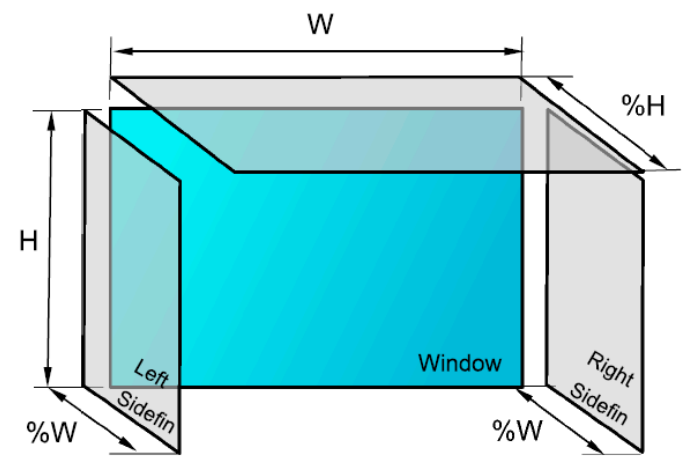

Figure 1. Shading device configurations.

Simulations have been developed for a full year, with five minute time steps, using an in-house code software based on the P\&C Methods [13], covering the eight main orientations (South, Southeast, East, Northeast, North, Northwest, West and Southeast); different window geometries (2 m wide $\times 1 \mathrm{~m}$ high and $1 \times 1 \mathrm{~m}$ ); several typologies of shading devices in the form of an overhang and/or two sidefins, varying so that the overhangs are as wide as the window and a length equal to $100 \%$, $75 \%, 25 \%$ or $0 \%$ of its height $(\mathrm{H})$, while sidefins are as high as the window and have a depth equal to $100 \%, 75 \%, 50 \%, 25 \%$ or $0 \%$ of its width (W); finally, different latitudes have been considered (Seville $[37.23 \circ \mathrm{N}]$, London $[51.1 \circ \mathrm{N}]$ and Whitehorse $[60.7 \circ \mathrm{N}])$. Solar radiation data for each simulated location have been extracted from the corresponding files provided by EnergyPlus [10]. Furthermore, the following angular discretization of the hemispherical sky has been used: $2^{\circ}$ and $10^{\circ}$ divisions for solar altitude and $2^{\circ}, 5^{\circ}, 10^{\circ}$ and $15^{\circ}$ for azimuth (Figure 2). A more detailed description can be found in Maestre et al. [15].

The set of study cases amounts to 6144 (Table 1). 

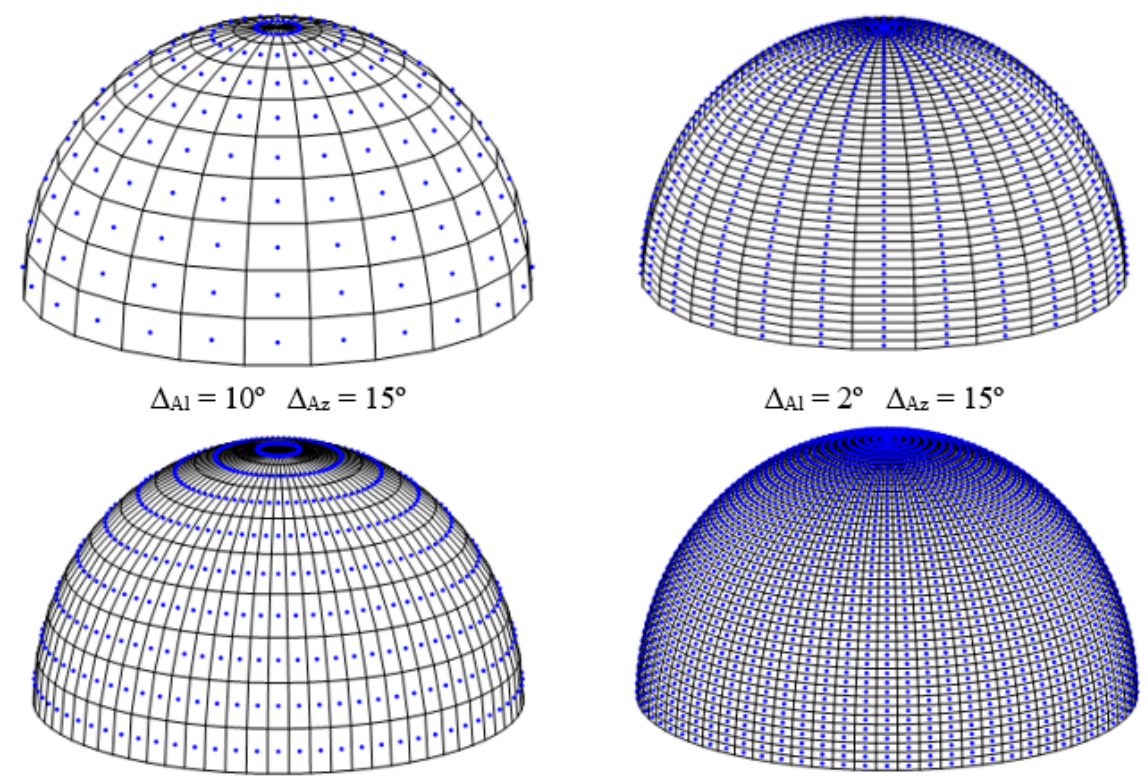

$\Delta \mathrm{Al}=10^{\circ} \quad \Delta_{\mathrm{Az}}=5^{\circ}$

$$
\Delta \mathrm{Al}=2^{\circ} \quad \Delta \mathrm{Az}=5^{\circ}
$$

Figure 2. Sky angular discretization.

Table 1. Combination of study cases.

\begin{tabular}{|c|c|c|c|c|c|c|c|}
\hline \multirow[b]{2}{*}{ Orientation } & \multirow{2}{*}{$\begin{array}{l}\text { Window Size } \\
\text { (Width }(\mathrm{m}) \times \\
\text { Height }(\mathrm{m}))\end{array}$} & \multirow{2}{*}{$\begin{array}{l}\text { Types of } \\
\text { Shading } \\
\text { Devices }\end{array}$} & \multicolumn{2}{|c|}{ Sizes of Shading Devices } & \multirow[b]{2}{*}{ Latitude } & \multicolumn{2}{|c|}{ Discretization } \\
\hline & & & Overhang & Sidefins & & $\begin{array}{c}\text { Solar } \\
\text { Altitude }\left({ }^{\circ}\right)\end{array}$ & Azimuth $\left(^{\circ}\right)$ \\
\hline South & \multirow{4}{*}{$2 \times 1$} & \multirow{3}{*}{ Overhang } & $100 \% \mathrm{H}$ & $100 \% \mathrm{~W}$ & \multirow{3}{*}{$37.23^{\circ} \mathrm{N}$} & \multirow{4}{*}{2} & \multirow{2}{*}{2} \\
\hline Southeast & & & & & & & \\
\hline East & & & $75 \% \mathrm{H}$ & $75 \% \mathrm{~W}$ & & & 5 \\
\hline Northeast & & \multirow{3}{*}{$\begin{array}{l}\text { Right } \\
\text { Sidefin }\end{array}$} & & & \multirow{3}{*}{$51.1^{\circ} \mathrm{N}$} & & \\
\hline North & \multirow{4}{*}{$1 \times 1$} & & $50 \% \mathrm{H}$ & $50 \% \mathrm{~W}$ & & \multirow{4}{*}{10} & \multirow[t]{2}{*}{10} \\
\hline Northwest & & & & & & & \\
\hline West & & \multirow[t]{2}{*}{$\begin{array}{c}\text { Left } \\
\text { Sidefin }\end{array}$} & $25 \% \mathrm{H}$ & $25 \% \mathrm{~W}$ & \multirow[t]{2}{*}{$60.7^{\circ} \mathrm{N}$} & & 15 \\
\hline & & & $0 \% \mathrm{H}$ & $0 \% \mathrm{~W}$ & & & \\
\hline
\end{tabular}

\subsection{Indicators}

In order to quantify the effect of the deviation in the pre-calculated solar position from the real position, some authors have proposed measuring the error in the estimation of the annual incident energy on the building [16]. However, to avoid the detected compensation of errors by Maestre et al. [15], it may be more appropriate to apply the methodology proposed by these authors. This methodology is that the deviation is measured through its effect on the so-called shading factor, $S F$, defined as the ratio between the global solar radiation received on a surface in the presence of shading obstacles and in their absence. From this idea, the authors define a weighted daily average error, $I$, as a measure of the error made in the estimation of incident solar radiation on the window

$$
I=\frac{\sum_{i=1}^{8760}\left|S F_{i}-S F_{i}^{*}\right| E_{i}}{\sum_{i=1}^{8760} S F_{i}^{*} E_{i}}=\frac{G-G^{*}}{G^{*}}=\frac{\Delta G}{G^{*}}
$$


where $S F_{i}$ is the shading factor corresponding to the closest position to the one pre-calculated at time $i$; $S F_{i}^{*}$ is the shading factor calculated at the exact solar position at the same time $i . E_{i}$ is the incident solar energy before the shading device at time $i$, expressed in $W / \mathrm{m}^{2}$. The denominator in Equation (1) is then the exact total solar radiation on the glazing, $G^{*}$, and the numerator is the associated absolute error, $\Delta G$, both expressed in terms of energy over glazed surface $\left(\mathrm{kWh} / \mathrm{m}^{2}\right)$.

It is worth noting that the present study assumes that the incident solar radiation is calculated at the simulation time, such that the main source of error is actually the difference in solar position.

This indicator is very useful in order to analyse the error as a function of orientation. In order to compare the rest of the variables, and assuming a geometrically symmetric building for each orientation, a global indicator $I_{g}$ is defined as follows

$$
I_{g}=\frac{\sum_{o=1}^{8} I_{o} G_{o}^{*}}{\sum_{o=1}^{8} G_{o}^{*}}
$$

where $I_{o}$ is the indicator $I$ corresponding to orientation $o$, and $G_{o}^{*}$ is the exact total incident energy on the window during a year at that orientation.

Although that symmetric building could not represent a typical building, its use is justified in order to set a common scenario with which comparisons of the different discretization levels can be made. The size of the building is not relevant, because the study only concentrates on the incident radiation on outer surfaces. Furthermore, indicators are non-dimensionalized by window surface.

The P\&C method proposed by Maestre et al. [13], which was validated by comparison with other methods, experimental results and European standards, has been used for the calculation of the shaded area. This method is based on the projection of polygons on a plane that is normal to sun rays, and subsequently finds the intersection by using the algorithm proposed by Vatti [23].

Data of direct solar radiation have been obtained from the weather files available in EnergyPlus [10].

In order to measure the computational cost of the method, some authors [16] propose the use of an absolute computational time. However, this indicator is strongly influenced by the type of computer and the programming language that are used. For that reason, a Normalised CPU Cost is considered in the present study. This indicator is defined as the ratio of the time required for shading calculation to the minimum time obtained, which is the time required for the less accurate discretization. For instance, a Normalised CPU Cost of 30 for $2^{\circ} \mathrm{Al}-5^{\circ} \mathrm{Az}$ discretization, implies that a resolution time of that case would be 30 times higher than the time required by the less accurate discretization, that is, $10^{\circ} \mathrm{Al}-15^{\circ} \mathrm{Az}$.

\section{Results}

Tables 2-6 show the overall results obtained for the different discretization levels considered in the present study. For reasons of symmetry, only the results for five orientations have been shown. The results have been divided into three groups: average $I$, maximum $I$ and maximum $\Delta G$. For each group, the weighted relative error $(I)$, annual solar radiation on the window $\left(G^{*}\right)$ and absolute error of incident energy $(\Delta G)$, all of them as a function of the discretization level.

Thus, for the first group and for each azimuth and solar altitude discretization level, the average values of all geometrical configurations and sites considered have been shown. As $G^{*}$ is the exact value of the incident solar energy on the window, it will not depend on the discretization level but on the orientation. For the second group, the maximum values of $I\left(I_{\max }\right)$ for each configuration are shown, together with the corresponding indicators $G^{*}$ and $\Delta G$. Finally, the third group shows the $I$ and $G^{*}$ values associated with the cases with maximum $\Delta G\left(\Delta G_{\max }\right)$.

It should be stressed that, for each discretization level, the configuration with the highest value of $I\left(I_{\max }\right)$ will not necessarily be the one with the highest $\Delta G\left(\Delta G_{\max }\right)$ value. For instance, it can be seen 
that for the South orientation and $2^{\circ} \mathrm{Al}-5^{\circ} \mathrm{Az}$ discretization, $I_{\text {max }}$ is 0.72 with an associated $\Delta G$ value of 1.41 , which corresponds to the following configuration: London, $1 \times 1 \mathrm{~m}^{2}$ window and $100 \%$ shading. However, the $\Delta G$ value for that configuration is not the maximum one $\left(\Delta G_{\max }\right)$, which is 2.25 and corresponds to the following configuration: Seville, $1 \times 1 \mathrm{~m}^{2}$ window and $25 \%$ shading. $I$ equals 0.33 in this case.

Table 2. Error indexes for each discretization level and the South orientation.

\begin{tabular}{|c|c|c|c|c|c|c|c|c|c|c|}
\hline \multicolumn{2}{|c|}{ Method } & \multicolumn{3}{|c|}{ Average I } & \multicolumn{3}{|c|}{ Maximum I } & \multicolumn{3}{|c|}{ Maximum $\Delta G$} \\
\hline $\begin{array}{l}\text { Al. } \\
\left({ }^{\circ}\right)\end{array}$ & $\begin{array}{l}\text { Az. } \\
\left({ }^{\circ}\right)\end{array}$ & $\begin{array}{c}I \\
(\%)\end{array}$ & $\begin{array}{c}\mathrm{G}^{*} \\
\left(\mathrm{kWh} / \mathrm{m}^{2}\right)\end{array}$ & $\begin{array}{c}\Delta \mathrm{G} \\
\left(\mathrm{kWh} / \mathrm{m}^{2}\right)\end{array}$ & $\begin{array}{l}I_{\max } \\
(\%)\end{array}$ & $\begin{array}{c}\mathrm{G}^{*} \\
\left(\mathrm{kWh} / \mathrm{m}^{2}\right)\end{array}$ & $\begin{array}{c}\Delta G \\
\left(\mathrm{kWh} / \mathrm{m}^{2}\right)\end{array}$ & $\begin{array}{c}I \\
(\%)\end{array}$ & $\begin{array}{c}\mathrm{G}^{*} \\
\left(\mathrm{kWh} / \mathrm{m}^{2}\right)\end{array}$ & $\begin{array}{c}\Delta \mathrm{G}_{\max } \\
\left(\mathrm{kWh} / \mathrm{m}^{2}\right)\end{array}$ \\
\hline 2 & 5 & 0.19 & 506.11 & 0.95 & 0.72 & 195.55 & 1.42 & 0.33 & 683.90 & 2.25 \\
\hline 2 & 10 & 0.35 & 506.11 & 1.76 & 1.28 & 294.14 & 3.75 & 0.89 & 496.41 & 4.44 \\
\hline 2 & 15 & 0.79 & 506.11 & 4.00 & 2.49 & 294.14 & 7.34 & 1.73 & 496.41 & 8.60 \\
\hline 10 & 2 & 1.56 & 506.11 & 7.91 & 5.59 & 169.53 & 9.48 & 4.82 & 342.01 & 16.50 \\
\hline 10 & 5 & 1.60 & 506.11 & 8.10 & 5.66 & 169.53 & 9.60 & 4.82 & 342.01 & 16.48 \\
\hline 10 & 10 & 1.68 & 506.11 & 8.49 & 5.75 & 169.53 & 9.74 & 4.88 & 342.01 & 16.69 \\
\hline 10 & 15 & 1.98 & 506.11 & 10.04 & 6.23 & 258.52 & 16.12 & 3.61 & 496.41 & 17.91 \\
\hline
\end{tabular}

Table 3. Error indexes for each discretization level and the Southeast orientation.

\begin{tabular}{|c|c|c|c|c|c|c|c|c|c|c|}
\hline \multicolumn{2}{|c|}{ Method } & \multicolumn{3}{|c|}{ Average I } & \multicolumn{3}{|c|}{ Maximum I } & \multicolumn{3}{|c|}{ Maximum $\Delta \mathrm{G}$} \\
\hline $\begin{array}{l}\text { Al. } \\
\left({ }^{\circ}\right)\end{array}$ & $\begin{array}{l}\text { Az. } \\
\left({ }^{\circ}\right)\end{array}$ & $\begin{array}{c}\text { I } \\
(\%)\end{array}$ & $\begin{array}{c}\mathrm{G}^{*} \\
\left(\mathrm{kWh} / \mathrm{m}^{2}\right)\end{array}$ & $\begin{array}{c}\Delta \mathrm{G} \\
\left(\mathrm{kWh} / \mathrm{m}^{2}\right)\end{array}$ & $\begin{array}{l}I_{\max } \\
(\%)\end{array}$ & $\begin{array}{c}\mathrm{G}^{*} \\
\left(\mathrm{kWh} / \mathrm{m}^{2}\right)\end{array}$ & $\begin{array}{c}\Delta G \\
\left(\mathrm{kWh} / \mathrm{m}^{2}\right)\end{array}$ & $\begin{array}{c}I \\
(\%)\end{array}$ & $\begin{array}{c}\mathrm{G}^{*} \\
\left(\mathrm{kWh} / \mathrm{m}^{2}\right)\end{array}$ & $\begin{array}{c}\Delta \mathrm{G}_{\max } \\
\left(\mathrm{kWh} / \mathrm{m}^{2}\right)\end{array}$ \\
\hline 2 & 5 & 0.16 & 513.97 & 0.84 & 0.57 & 259.53 & 1.48 & 0.47 & 418.53 & 1.95 \\
\hline 2 & 10 & 0.33 & 513.97 & 1.68 & 1.38 & 259.53 & 3.59 & 1.20 & 348.44 & 4.18 \\
\hline 2 & 15 & 0.74 & 513.97 & 3.78 & 2.47 & 311.21 & 7.70 & 1.70 & 535.61 & 9.09 \\
\hline 10 & 2 & 1.20 & 513.97 & 6.19 & 4.67 & 242.45 & 11.31 & 4.16 & 345.39 & 14.36 \\
\hline 10 & 5 & 1.24 & 513.97 & 6.40 & 4.73 & 242.45 & 11.48 & 4.17 & 345.39 & 14.42 \\
\hline 10 & 10 & 1.32 & 513.97 & 6.81 & 4.91 & 242.45 & 11.91 & 4.17 & 345.39 & 14.42 \\
\hline 10 & 15 & 1.62 & 513.97 & 8.32 & 5.35 & 242.45 & 12.98 & 2.94 & 535.61 & 15.75 \\
\hline
\end{tabular}

Table 4. Error indexes for each discretization level and the East orientation.

\begin{tabular}{|c|c|c|c|c|c|c|c|c|c|c|}
\hline \multicolumn{2}{|c|}{ Method } & \multicolumn{3}{|c|}{ Average I } & \multicolumn{3}{|c|}{ Maximum I } & \multicolumn{3}{|c|}{ Maximum $\Delta G$} \\
\hline $\begin{array}{l}\text { Al. } \\
\left({ }^{\circ}\right)\end{array}$ & $\begin{array}{l}\text { Az. } \\
\left({ }^{\circ}\right)\end{array}$ & $\begin{array}{c}I \\
(\%)\end{array}$ & $\begin{array}{c}\mathrm{G}^{*} \\
\left(\mathrm{kWh} / \mathrm{m}^{2}\right)\end{array}$ & $\begin{array}{c}\Delta \mathrm{G} \\
\left(\mathrm{kWh} / \mathrm{m}^{2}\right)\end{array}$ & $\begin{array}{c}I_{\max } \\
(\%)\end{array}$ & $\begin{array}{c}\mathrm{G}^{*} \\
\left(\mathrm{kWh} / \mathrm{m}^{2}\right)\end{array}$ & $\begin{array}{c}\Delta \mathrm{G} \\
\left(\mathrm{kWh} / \mathrm{m}^{2}\right)\end{array}$ & $\begin{array}{c}\mathrm{I} \\
(\%)\end{array}$ & $\begin{array}{c}\mathrm{G}^{*} \\
\left(\mathrm{kWh} / \mathrm{m}^{2}\right)\end{array}$ & $\underset{\left(\mathrm{kWh} / \mathrm{m}^{2}\right)}{\Delta \mathrm{G}_{\max }}$ \\
\hline 2 & 5 & 0.15 & 383.66 & 0.57 & 0.66 & 286.62 & 1.89 & 0.66 & 286.62 & 1.89 \\
\hline 2 & 10 & 0.30 & 383.66 & 1.14 & 1.04 & 286.62 & 3.00 & 1.04 & 286.62 & 3.00 \\
\hline 2 & 15 & 0.66 & 383.66 & 2.52 & 2.76 & 286.62 & 7.91 & 2.76 & 286.62 & 7.91 \\
\hline 10 & 2 & 0.79 & 383.66 & 3.03 & 2.65 & 249.39 & 6.61 & 2.65 & 249.39 & 6.61 \\
\hline 10 & 5 & 0.83 & 383.66 & 3.20 & 2.65 & 188.08 & 4.98 & 2.65 & 249.39 & 6.60 \\
\hline 10 & 10 & 0.92 & 383.66 & 3.52 & 2.71 & 188.08 & 5.10 & 2.07 & 343.33 & 7.10 \\
\hline 10 & 15 & 1.22 & 383.66 & 4.68 & 3.83 & 286.62 & 10.99 & 3.83 & 286.62 & 10.99 \\
\hline
\end{tabular}

Table 5. Error indexes for each discretization level and the Northeast orientation.

\begin{tabular}{|c|c|c|c|c|c|c|c|c|c|c|}
\hline \multicolumn{2}{|c|}{ Method } & \multicolumn{3}{|c|}{ Average I } & \multicolumn{3}{|c|}{ Maximum I } & \multicolumn{3}{|c|}{ Maximum $\Delta \mathrm{G}$} \\
\hline $\begin{array}{l}\text { Al. } \\
\left({ }^{\circ}\right)\end{array}$ & $\begin{array}{l}\text { Az. } \\
\left({ }^{\circ}\right)\end{array}$ & $\begin{array}{c}\text { I } \\
(\%)\end{array}$ & $\begin{array}{c}\mathrm{G}^{*} \\
\left(\mathrm{kWh} / \mathrm{m}^{2}\right)\end{array}$ & $\begin{array}{c}\Delta \mathrm{G} \\
\left(\mathrm{kWh} / \mathrm{m}^{2}\right)\end{array}$ & $\begin{array}{c}I_{\max } \\
(\%)\end{array}$ & $\begin{array}{c}\mathrm{G}^{*} \\
\left(\mathrm{kWh} / \mathrm{m}^{2}\right)\end{array}$ & $\begin{array}{c}\Delta \mathrm{G} \\
\left(\mathrm{kWh} / \mathrm{m}^{2}\right)\end{array}$ & $\begin{array}{c}\text { I } \\
(\%)\end{array}$ & $\begin{array}{c}\mathrm{G}^{*} \\
\left(\mathrm{kWh} / \mathrm{m}^{2}\right)\end{array}$ & $\begin{array}{c}\Delta \mathrm{G}_{\max } \\
\left(\mathrm{kWh} / \mathrm{m}^{2}\right)\end{array}$ \\
\hline 2 & 5 & 0.24 & 146.41 & 0.35 & 0.67 & 62.96 & 0.42 & 0.44 & 184.99 & 0.81 \\
\hline 2 & 10 & 0.54 & 146.41 & 0.79 & 1.74 & 89.60 & 1.56 & 0.96 & 184.99 & 1.77 \\
\hline 2 & 15 & 1.63 & 146.41 & 2.38 & 4.43 & 62.96 & 2.79 & 3.91 & 135.07 & 5.28 \\
\hline 10 & 2 & 0.76 & 146.41 & 1.11 & 2.56 & 90.21 & 2.31 & 2.56 & 90.21 & 2.31 \\
\hline 10 & 5 & 0.83 & 146.41 & 1.21 & 2.62 & 90.21 & 2.36 & 2.62 & 90.21 & 2.36 \\
\hline 10 & 10 & 1.01 & 146.41 & 1.47 & 2.79 & 90.21 & 2.51 & 2.79 & 90.21 & 2.51 \\
\hline 10 & 15 & 1.94 & 146.41 & 2.84 & 5.12 & 80.44 & 4.12 & 4.15 & 135.07 & 5.61 \\
\hline
\end{tabular}


Table 6. Error indexes for each discretization level and the North orientation.

\begin{tabular}{|c|c|c|c|c|c|c|c|c|c|c|}
\hline \multicolumn{2}{|c|}{ Method } & \multicolumn{3}{|c|}{ Average I } & \multicolumn{3}{|c|}{ Maximum I } & \multicolumn{3}{|c|}{ Maximum $\Delta \mathrm{G}$} \\
\hline $\begin{array}{l}\text { Al. } \\
\left({ }^{\circ}\right)\end{array}$ & $\begin{array}{l}\text { Az. } \\
\left({ }^{\circ}\right)\end{array}$ & $\begin{array}{c}\text { I } \\
(\%)\end{array}$ & $\begin{array}{c}\mathrm{G}^{*} \\
\left(\mathrm{kWh} / \mathrm{m}^{2}\right)\end{array}$ & $\underset{\left(k W h / m^{2}\right)}{\Delta G}$ & $\begin{array}{c}I_{\max } \\
(\%)\end{array}$ & $\begin{array}{c}\mathrm{G}^{*} \\
\left(\mathrm{kWh} / \mathrm{m}^{2}\right)\end{array}$ & $\begin{array}{c}\Delta \mathrm{G} \\
\left(\mathrm{kWh} / \mathrm{m}^{2}\right)\end{array}$ & $\begin{array}{c}I \\
(\%)\end{array}$ & $\begin{array}{c}\mathrm{G}^{*} \\
\left(\mathrm{kWh} / \mathrm{m}^{2}\right)\end{array}$ & $\begin{array}{c}\Delta \mathrm{G}_{\max } \\
\left(\mathrm{kWh} / \mathrm{m}^{2}\right)\end{array}$ \\
\hline 2 & 5 & 0.42 & 21.97 & 0.09 & 2.68 & 6.30 & 0.17 & 2.38 & 14.48 & 0.34 \\
\hline 2 & 10 & 0.80 & 21.97 & 0.18 & 5.75 & 14.48 & 0.83 & 5.75 & 14.48 & 0.83 \\
\hline 2 & 15 & 3.89 & 21.97 & 0.85 & 22.68 & 8.85 & 2.01 & 21.14 & 14.82 & 3.13 \\
\hline 10 & 2 & 2.11 & 21.97 & 0.46 & 14.44 & 5.19 & 0.75 & 14.44 & 5.19 & 0.75 \\
\hline 10 & 5 & 2.30 & 21.97 & 0.51 & 14.64 & 5.19 & 0.76 & 14.64 & 5.19 & 0.76 \\
\hline 10 & 10 & 2.52 & 21.97 & 0.55 & 15.31 & 5.19 & 0.79 & 5.77 & 14.82 & 0.85 \\
\hline 10 & 15 & 5.10 & 21.97 & 1.12 & 23.87 & 8.85 & 2.11 & 22.60 & 14.82 & 3.35 \\
\hline
\end{tabular}

From a preliminary analysis, it can be seen that $\Delta G_{\max }$ is about $17.91 \mathrm{kWh} / \mathrm{m}^{2}$ (Table 2) for the South orientations, representing 3.6\% of its associated $G^{*}$ value. Likewise, for the Southeast orientation, $\Delta G_{\max }$ is $15.42 \mathrm{kWh} / \mathrm{m}^{2}$ (Table 3) ( $3 \%$ of its corresponding $\left.G^{*}\right)$. For the North orientation, the highest value of $\Delta G_{\max }$ amounts to $3.35 \mathrm{kWh} / \mathrm{m}^{2}$ (Table 6), representing $22.6 \%$ of the total incident energy.

Next, a careful analysis of the influence of the differing variants studied is developed.

\subsection{Influence of the Solar Altitude and Azimuth Discretization}

Figure 3 shows the variation in the $I$ average values for changes of $10^{\circ}$ and $8^{\circ}$ in solar altitude and azimuth discretization levels, respectively, for the different orientations. It is noted that error is more sensitive to altitude discretization level than to azimuth discretization level for the South orientation. Thus, for that orientation, an increase of $10^{\circ}$ of the azimuth discretization level (from $2^{\circ} \mathrm{Al}-5^{\circ} \mathrm{Az}$ to $2^{\circ} \mathrm{Al}-15^{\circ} \mathrm{Az}$ ) leads to an increase in the $I$ average values from $0.19 \%$ to $0.79 \%$, that is, more than four times greater. Similarly, from $2^{\circ} \mathrm{Al}-5^{\circ} \mathrm{Az}$ to $10^{\circ} \mathrm{Al}-5^{\circ} \mathrm{Az}$ (with an increase of $8^{\circ}$ in solar altitude and a $5^{\circ}$ azimuth discretization), I changes from $0.19 \%$ to $1.6 \%$, more than eight times greater. However, the increase in $I$ for the North orientation is even greater than for the South orientation, where changes of $10^{\circ}$ and $8^{\circ}$ in azimuth and solar altitude discretization levels lead to $I$ values 9 and 5 times greater, respectively.

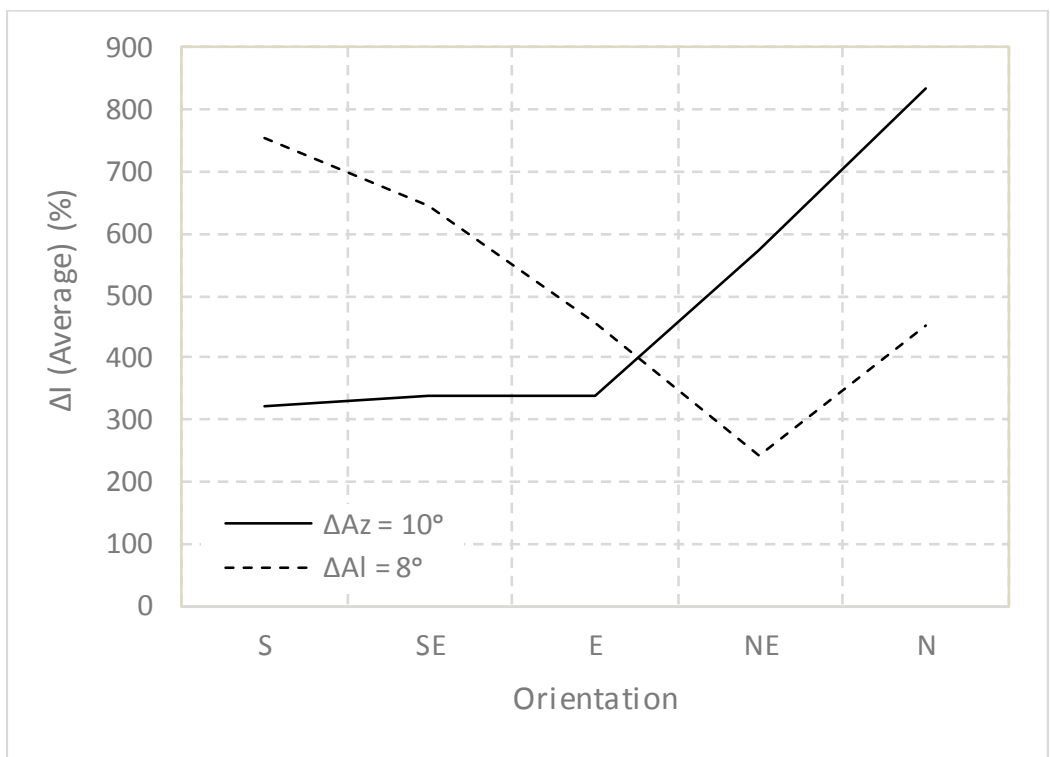

Figure 3. Influence of orientation and angular discretization on average $I$ values.

The maximum absolute error $\left(\Delta G_{\max }\right)$ is about $17.91 \mathrm{kWh} / \mathrm{m}^{2}$, which corresponds to the least accurate discretization: Seville, $1 \times 1 \mathrm{~m}^{2}$ window, 50\% shading and the South orientation. Figure 4 shows the shade fraction (1-SF) on the window for that day considering $10^{\circ} \mathrm{Al}-15^{\circ} \mathrm{Az}$ discretization, 
together with the exact value (called reference) which is calculated from the actual sun position. Sudden changes in the sunlit surface fraction can be observed due to the effect of angular discretization, that is, to the discrete variation in solar position. The associated absolute error of incident energy is also shown. In this case, the time with the highest absolute error $\left(5.76 \mathrm{Wh} / \mathrm{m}^{2}\right)$ is 4 April, 11:40 a.m. local time.

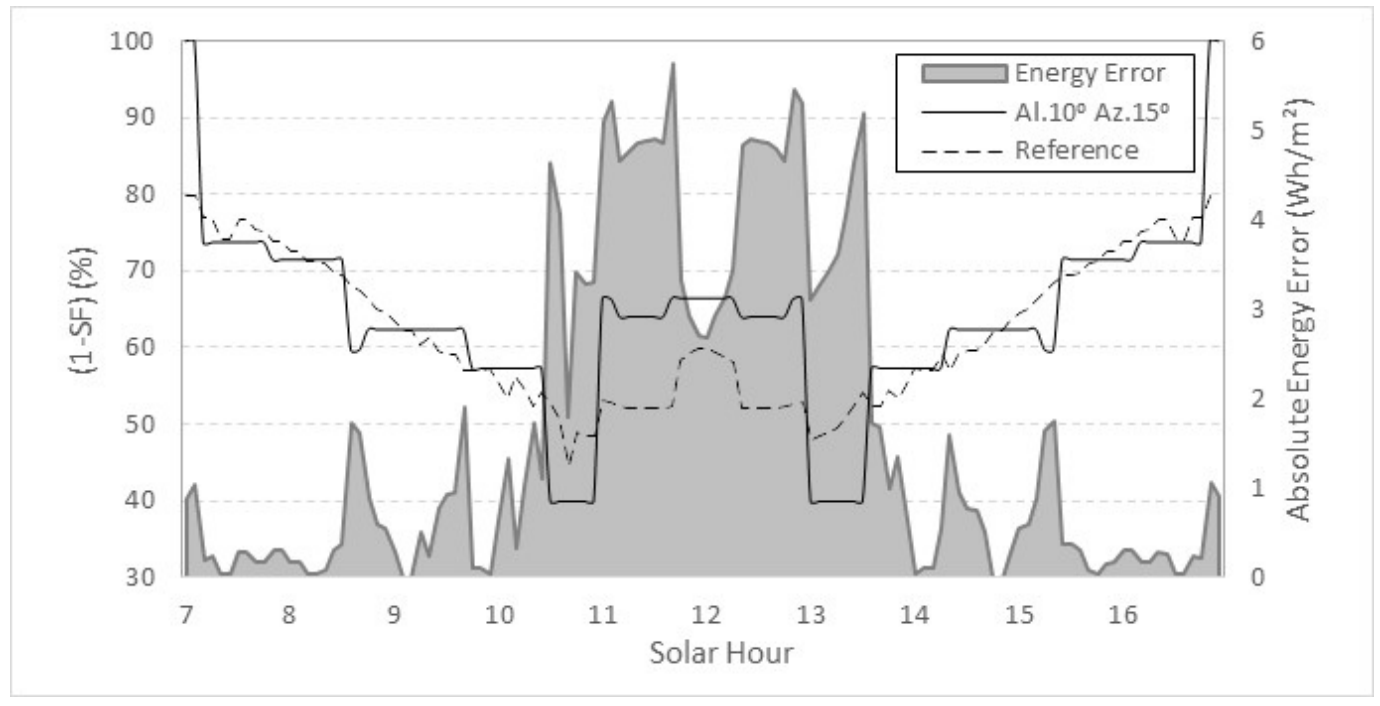

Figure 4. Shading fraction (1-SF) on 4 April, at Seville.

For this case, the shading factor at 11:00 a.m. is 0.51 (azimuth and solar altitude are $26.82^{\circ}$ and $55.16^{\circ}$, respectively). The corresponding projected shade can be seen in Figure 5. Figure $5 \mathrm{~b}$ shows the projected shade when an increase of $5^{\circ}$ in the previous azimuth value is considered, obtaining a value of 0.50 for the shading factor ( $1.96 \%$ of error). Analogously, the effect on the projected shade due to the same angular increase $\left(5^{\circ}\right)$ in solar altitude is shown in Figure $5 c$, leading to a shading factor of 0.66 (29.4\% of error).

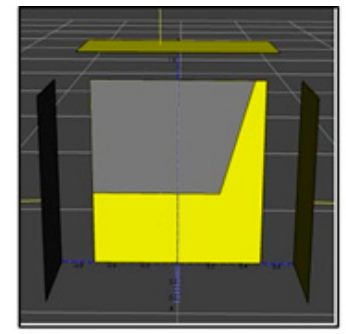

(a)

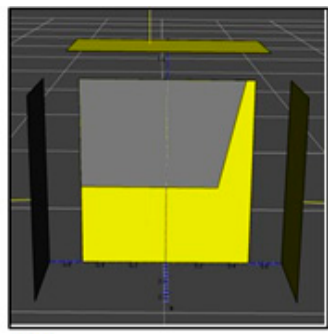

(b)

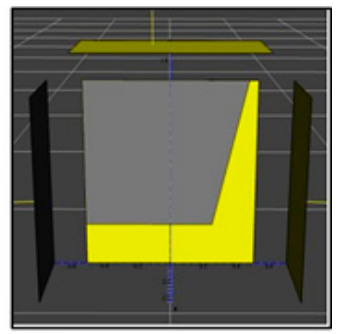

(c)

Figure 5. Shade pattern at: (a) 11:00 a.m.; (b) 11:00 a.m., considering a variation of $+5^{\circ}$ in the azimuth reference value; (c) 11:00 a.m., considering a variation of $+5^{\circ}$ in the solar altitude reference value.

For the sun positions in which sidefin devices lead to shades over the window (e.g., at 16:00 local time; azimuth $75.13^{\circ}$ and solar altitude $26.83^{\circ}$ ), the same angular variation in azimuth ( $5^{\circ}$ ) leads to an error of $1.37 \%$ in SF, while a similar variation in solar altitude leads to a $4 \%$ error. Thus, the projected shading calculations from sidefins are less sensitive to the discretization level. This is mainly due to the fact that sidefins are not influenced by solar altitude because they are upright.

\subsection{Influence of the Shading Device Typology}

The global distribution of $I_{g}$ for all cases, in terms of discretization level and shading devices, is shown as a box plot in Figure 6. According to Tukey [24] definitions, a thin box marks out the 
25th to 75th percentiles, a line within the box marks the median, and a line marks the outer part of the distribution.

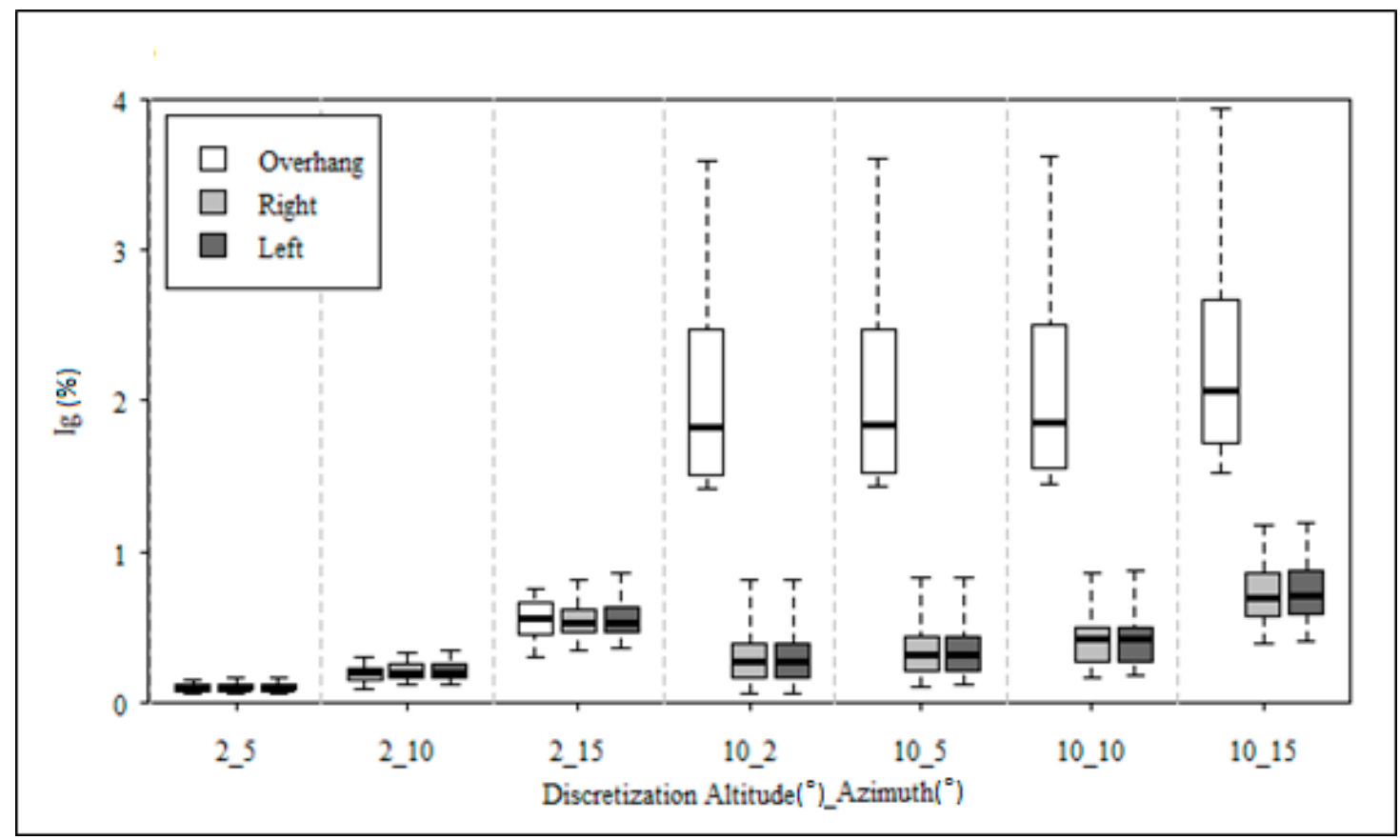

Figure 6. $I_{g}$ distribution as a function of discretization for different types of shading devices.

It can be seen that the type of shading device does not impact on $I_{g}$ values for configurations with $2^{\circ}$ azimuth discretization levels, since $I_{g}$ distributions are very similar. $I_{g}$ dispersion slightly increases with the increase in azimuth discretization, with a median value of about $0.4 \%$ for the three types of shading device. However, unsurprisingly, altitude discretization has a more significant influence on overhangs than on sidefins, where the former trend caused by the change in azimuth discretization still remains. Thus, for overhangs, the situation changes from a maximum error smaller than $1 \%$ for $2^{\circ}$ discretization, to errors up to $4 \%$ for $10^{\circ}$ altitude discretization. The results for left and right sidefins are almost identical and the small differences are due to the dependence of radiation on cloud cover.

\subsection{Influence of Latitude and Orientation}

Figure 7 shows the variation in $I_{g}$ as a function of location. Although a deeper study that included more locations at a given latitude would be necessary to draw firm conclusions, it seems there is no significant influence of latitude on the median values of this indicator for the three locations considered. However, an increase of maximum values is observed, reaching a value of $4.74 \%$ for Whitehorse $\left(60.7^{\circ} \mathrm{N}\right), 10^{\circ}$ and $15^{\circ}$ altitude and azimuth discretization, respectively, $2 \mathrm{~m}^{2}$ window and $100 \%$ shading.

The highest value of $I_{\max }(23.87 \%)$ is found for the North orientation. However, the high relative errors are associated with small incident energies. Thus, the corresponding absolute energy error is $2.11 \mathrm{kWh} / \mathrm{m}^{2}$, in contrast to the value of $16.12 \mathrm{kWh} / \mathrm{m}^{2}$ obtained for the South orientation and its maximum $I$ value. In this respect, it is observed that $\Delta G_{\text {max }}$ for the North orientation is $3.35 \mathrm{kWh} / \mathrm{m}^{2}$, much less than for the South, with a value of $17.91 \mathrm{kWh} / \mathrm{m}^{2}$. However, the relative error associated with these values is $22.60 \%$ for the North orientation in contrast to the $3.61 \%$ for the South. Figure 8 shows the daily variation in $I$ calculated for one day $\left(I_{d}\right)$ and the absolute error of the daily incident energy $\left(\Delta G_{d}\right)$ for the Seville, $1 \times 1 \mathrm{~m}^{2}$ window and $50 \% \mathrm{H}$ overhang and $50 \% \mathrm{~W}$ sidefins, illustrating the amplification of relative error due to small quantities of incident energy on the window for a particular case. 


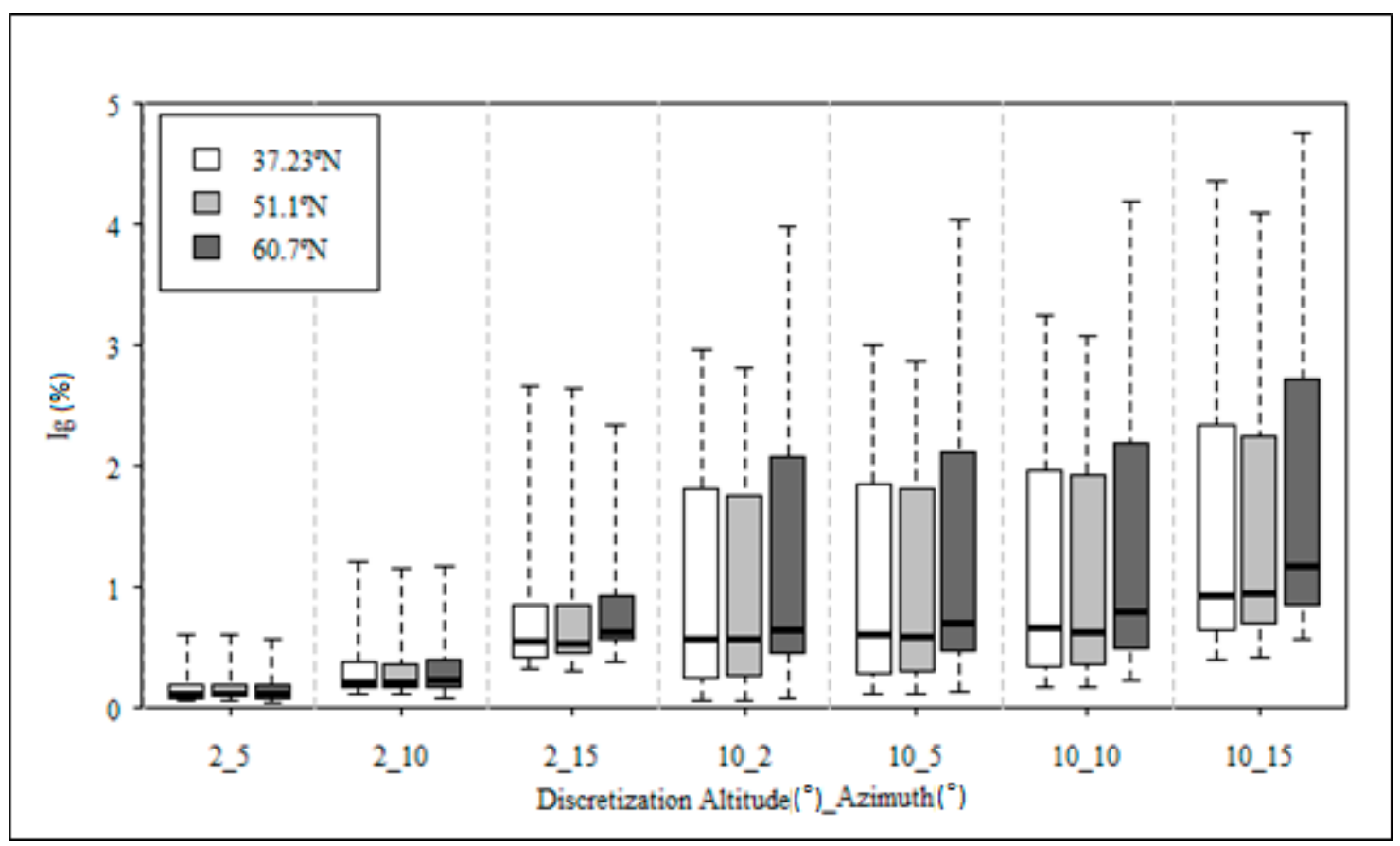

Figure 7. $I_{g}$ distribution for different locations.

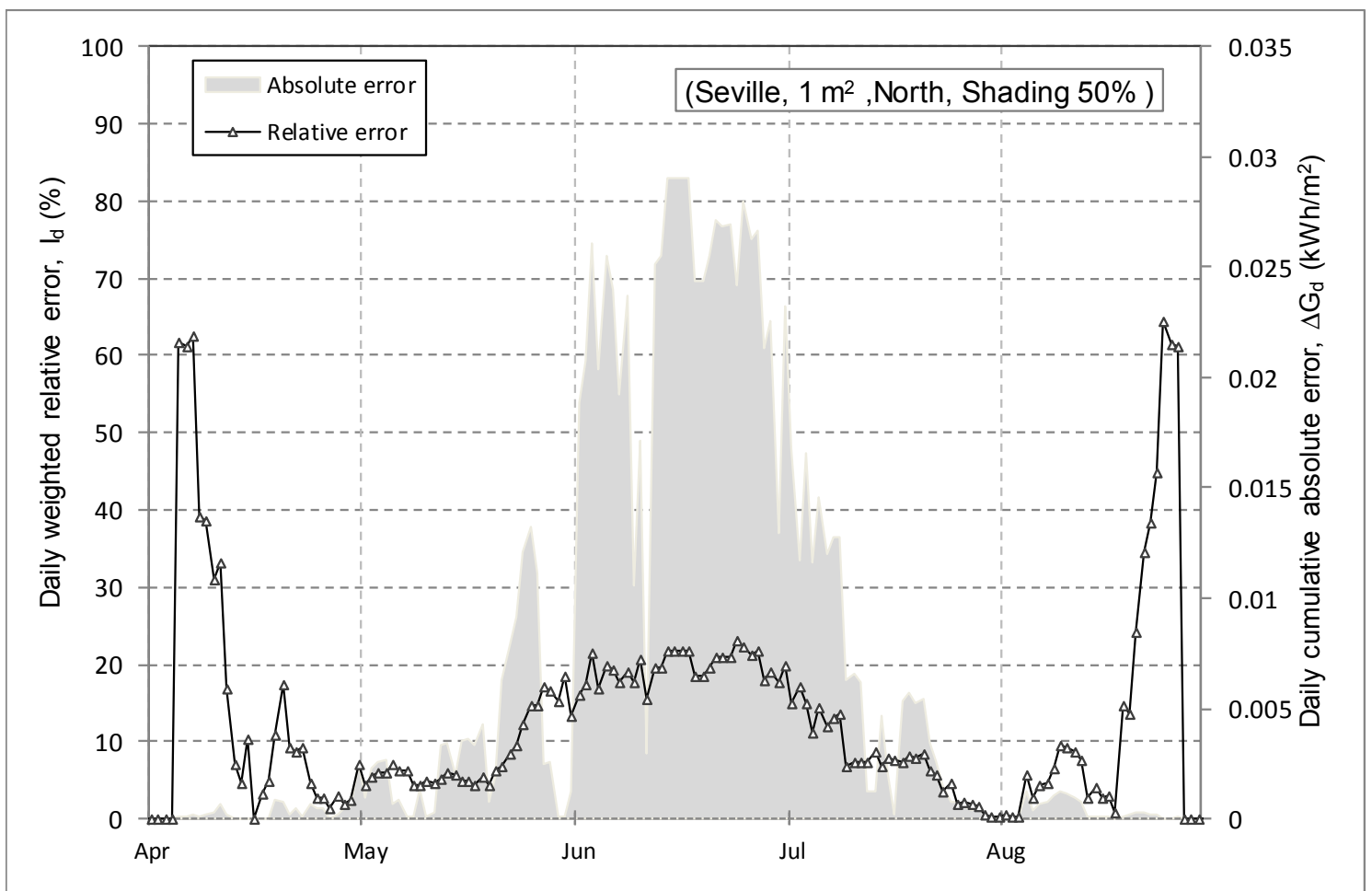

Figure 8. Time evolution of $I_{d}$ and $\Delta G_{d}$.

\subsection{Influence on CPU Time}

Figure 9 shows the Normalized CPU Cost and maximum $I_{g}$ values obtained in all simulations. Computational cost will depend on location because, during the shading calculation process, it is possible to exclude discrete positions where the sun will never be and to select only the right ones in advance. Figure 9 also shows the computational cost when that selection is not taken into account. It is known that the associated computational cost is directly proportional to the number of positions 
in each level of angular discretization. Thus, it is observed that the computational cost associated with the most accurate discretization is about 20 times the one obtained with the least one, on average. Furthermore, the maximum error of $I_{g}$ associated with the least accurate discretization increases about eight times with respect to the most accurate one.

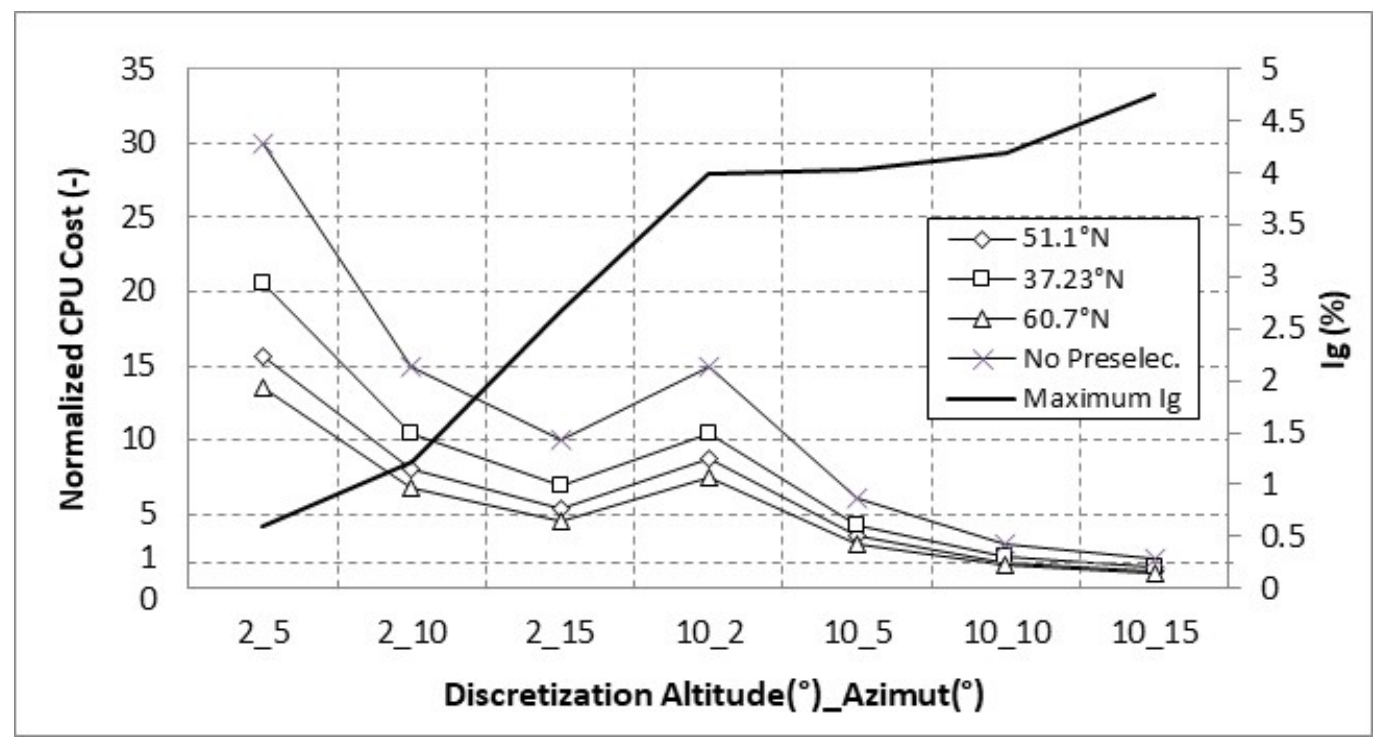

Figure 9. Normalized CPU cost and $I_{g}$ max error indicator for different discretization levels.

On average, maximum $I_{g}$ values increase by 1.6 and four times for each $5^{\circ}$ and $8^{\circ}$ azimuth and altitude increase, respectively. This result suggests that the maximum $I_{g}$ values are more sensitive to altitude than to azimuth variations. Thus, for a $2^{\circ}$ altitude discretization, average indexes of normalized CPU cost and $I_{g}$ values are 10 and 1.49 , respectively, while for a $10^{\circ}$ altitude discretization, the former variables are 2.2 and 4.3 , respectively.

Moreover, the average increase in the normalized CPU cost is about 3.6 for a $5^{\circ}$ azimuth increase.

The average saving obtained after a preliminary selection (pre-selection) is up to $50 \%$, approximately. However, in terms of absolute values, saving is greater for more accurate discretization levels, achieving a value of 13.4 , while it is about 2 for $10^{\circ} \mathrm{Al}-15^{\circ} \mathrm{Az}$. Then, the pre-selection process is more justified for the most accurate discretizations.

The required computational effort increases by 1 and 0.7 points, on average, for every $1^{\circ}$ increase in altitude and azimuth discretization level, respectively, due to the higher number of hemispherical sky divisions. However, maximum $I_{g}$ decreases by $27 \%$ on average for a given altitude variation with respect to the same azimuth variation.

By way of illustration, in a building with a geometry defined by 177 polygons, 99 ms would be necessary to obtain the corresponding shades for each solar position [25]. Considering the results shown in Figure 9, the number of sun positions required, after the pre-selection process and by using $2^{\circ} \mathrm{Al}-5^{\circ} \mathrm{Az}$ instead of $10^{\circ} \mathrm{Al}-5^{\circ} \mathrm{Az}$, would increase from 376 to 1692 . This would allow for reducing the error of incident solar radiation from $4 \%$ to $0.6 \%$, with an increase of only 2.2 min in an annual simulation. Obviously, this increase in absolute computational time will become smaller as computer capacity improves and the viability of its application will depend on the type of ongoing study (design, optimization, parametric analysis, energy labelling, etc.).

\section{Conclusions}

The most widespread building energy performance simulation programs still have some simplified strategies that were developed to reduce the computation time associated with the algorithms used for shading calculations. Some of these simplifications are to calculate shades during a representative day 
of a certain period of time (twenty or thirty days) or to make shading calculations only for some solar positions after a discretization process of the hemispherical sky.

The present work studies the influence of the discretization level of the hemispherical sky on the estimation of incident direct radiation on building surfaces and also on the required computation time. Different window sizes, overhang and sidefins typologies, latitudes and shading devices orientations, which have led to more than 6000 configurations, have been analysed. A weighted average value considering the eight main orientations has been used in order to measure the error for incident radiation.

In terms of annual incident solar energy, the results show that the maximum error values are about $5 \%$ if a low level of angular discretization (altitude, $10^{\circ}$; azimuth, $15^{\circ}$ ) is used. These error values are smaller than $1 \%$ for all configurations when a more accurate discretization (altitude, $2^{\circ}$; azimuth, $5^{\circ}$ ) is considered. Although annual average errors seem to be not significant, a great number of the configurations analysed show errors of shading factor on a window up to $30 \%$ in solar positions with high values of incident radiation, if a low level of angular discretization is taken into account.

From a study of computation time, it is estimated that an increase of only two minutes is required in order to achieve a correct shading calculation in building energy simulation programs. Thus, considering the continuous evolution of computation capacity, it seems unreasonable to keep the current error associated with the algorithms used in this kind of simulation program.

Authors think that a future development would be the optimisation of the hemispherical sky mesh by applying a previous algorithm which is able to decide on the local discretization level depending on location and orientation.

Author Contributions: Conceptualization, I.R.M.; methodology, I.R.M. and J.L.F.B.; software, J.L.F.B.; validation, J.L.F.B., F.J.G.G. and J.D.M.B.; investigation, F.J.G.G. and J.D.M.B.; writing-original draft preparation, J.L.F.B.; writing-review and editing, F.J.G.G. All authors have read and agreed to the published version of the manuscript.

Funding: This research received no external funding.

Conflicts of Interest: The authors declare no conflict of interest.

\section{Nomenclature}

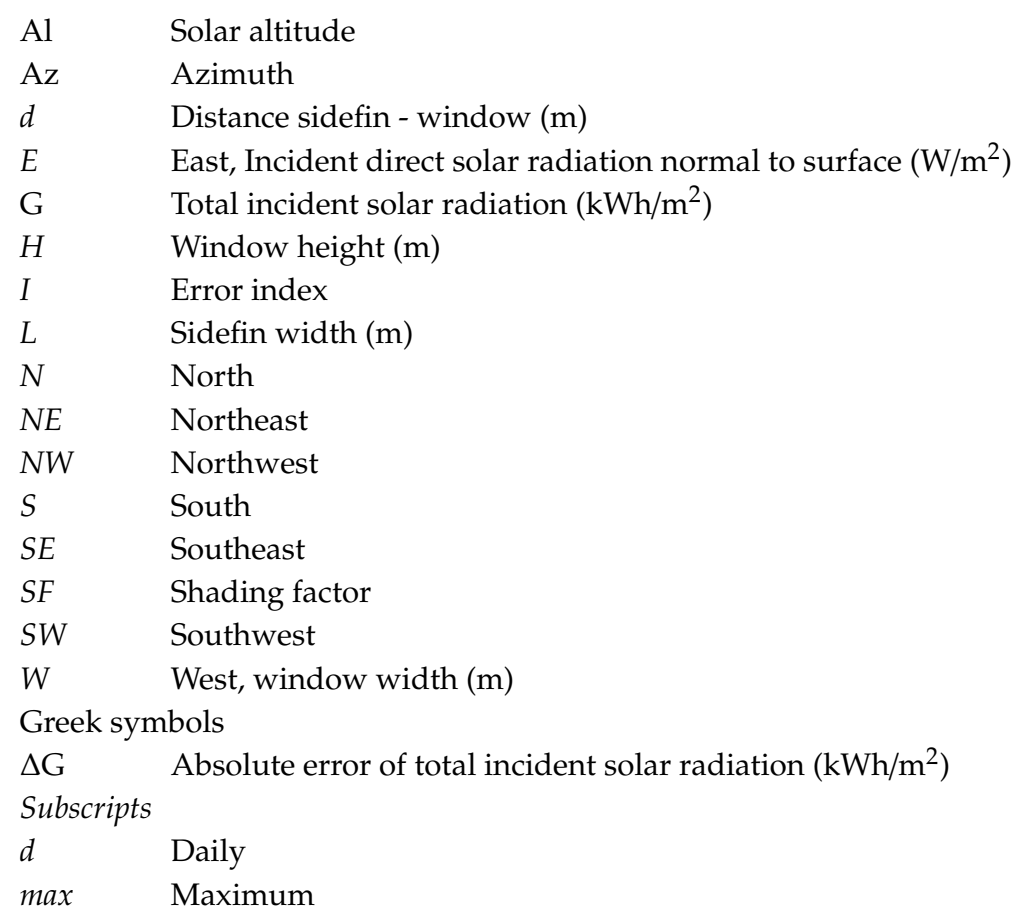


g Global discretization error

$i \quad$ Time index

o Orientation

Superscripts

* Reference

\section{References}

1. Kirimtat, A.; Koyunbaba, B.K.; ChatziKonstantinou, I.; Sariyildiz, S. Review of simulation modeling for shading devices in buildings. Renew. Sustain. Energy Rev. 2016, 53, 23-49. [CrossRef]

2. Bellia, L.; Marino, C.; Minichiello, F.; Pedace, A. An overview on solar shading systems for buildings. Energy Procedia 2014, 62, 309-317. [CrossRef]

3. Tzempelikos, A.; Athienitis, A.K. The impact of shading design and control on building cooling and lighting demand. Sol. Energy 2007, 81, 369-382. [CrossRef]

4. Xiong, J.; Tzempelikos, A. Model-based shading and lighting controls considering visual comfort and energy use. Solar Energy 2016, 134, 416-428. [CrossRef]

5. Mettanant, V.; Chaiwiwatworakul, P. Automated vertical blinds for daylighting in tropical region. Energy Procedia 2014, 52, 278-286. [CrossRef]

6. Abdel-Ghany, A.; Al-Helal, I.; Alkoaik, F.; Alsadon, A.; Shady, M.; Ibrahim, A. Predicting the Cooling Potential of Different Shading Methods for Greenhouses in Arid Regions. Energies 2019, 12, 4716. [CrossRef]

7. Choi, J.H.; Loftness, V.; Nou, D.; Tinianov, B.; Yeom, D. Multi-Season Assessment of Occupant Responses to Manual Shading and Dynamic Glass in a Workplace Environment. Energies 2020, 13, 60. [CrossRef]

8. Shin, M.; Haberl, J.S. Thermal zoning for building HVAC design and energy simulation: A literature review. Energy Build. 2019, 203, 109429. [CrossRef]

9. Crawley, D.B.; Hand, J.W.; Kummert, M.; Griffith, B.T. Contrasting the capabilities of building energy performance simulation programs. Build. Environ. 2008, 43, 661-673. [CrossRef]

10. EnergyPlus ${ }^{\mathrm{TM}}$ Version 8.9.0 Documentation. Engineering Reference. U.S. Department of Energy. March 2018. Available online: https://energyplus.net/sites/all/modules/custom/nrel_custom/pdfs/pdfs_v8.9.0/ EngineeringReference.pdf (accessed on 15 March 2020).

11. Birdsall, B.; Buhl, W.F.; Ellington, K.L.; Erdem, A.E.; Winkelmann, F.C. Overview of the DOE-2 Building Energy Analysis Program, Version 2.1 D; Laurence Berkeley Laboratoy, University of California: Berkeley, CA, USA, 1990.

12. TRNSYS. TRNSYS 17 Reference Manual; Solar Energy Laboratory, University of Wisconsin-Madison: Madison, WI, USA, 2012.

13. Maestre, I.R.; Pérez-Lombard, L.; Foncubierta, J.L.; Cubillas, P.R. Improving direct solar shading calculations within building energy simulation tools. J. Build. Perform. Simul. 2013, 6, 437-448. [CrossRef]

14. de Almeida Rocha, A.P.; Oliveira, R.C.; Mendes, N. Experimental validation and comparison of direct solar shading calculations within building energy simulation tools: Polygon clipping and pixel counting techniques. Sol. Energy 2017, 158, 462-473. [CrossRef]

15. Maestre, I.R.; Foncubierta Blázquez, J.L.; González Gallero, F.J.; Cubillas, P.R. Influence of selected solar positions for shading device calculations in building energy performance simulations. Energy Build. 2015, 10, 144-152. [CrossRef]

16. Jones, N.L.; Greenberg, D.P.; Pratt, K.B. Fast computer graphics techniques for calculating direct solar radiation on complex building surfaces. J. Build. Perform. Simul. 2012, 5, 300-312. [CrossRef]

17. Cheung, H.; Chung, T. Analyzing sunlight duration and optimum shading using a sky map. Build. Environ. 2007, 42, 3138-3148. [CrossRef]

18. British Standards. Lighting for Buildings, Part 2. Code of Practice for Daylighting. BS8206: Part 2; British Standards Institution: London, UK, 1992.

19. Sánchez de la Flor, F.J.; Ortiz Cebolla, R.; Molina Félix, J.L.; Álvarez Domínguez, S. Solar radiation calculation methodology for building exterior surfaces. Sol. Energy 2005, 79, 513-522. [CrossRef]

20. Tregenza, P.R.; Mcibse, R. Subdivision of the sky hemisphere for luminance measurements. Light. Res. Technol. 1987, 19, 13-14. [CrossRef] 
21. Bourgeois, D.; Reinhart, C.F.; Ward, G. A Standard Daylight Coefficient Model for Dynamic Daylighting Simulations. Build. Res. Inf. 2008, 36, 68-82. [CrossRef]

22. Winkelmann, F.C.; Selkowitz, S. Daylighting Simulation in the DOE-2 Building Energy Analysis Program. Energy Build. 1985, 8, 271-286. [CrossRef]

23. Vatti, B. A generic solution to polygon clipping. Commun. Assoc. Comput. Mach. 1992, 7, 56-63. [CrossRef]

24. Tukey, J.W. Exploratory Data Analysis; Addison-Wesley Publishing Company Reading: Boston, MA, USA; Menlo Park, CA, USA; London, UK; Amsterdam, The Netherlands; Don Mills, ON, Canada; Sydney, Australia, 1977.

25. Cascone, Y.; Corrado, V.; Serra, V. Calculation procedure of the shading factor under complex boundary conditions. Sol. Energy 2011, 85, 2524-2539. [CrossRef]

(C) 2020 by the authors. Licensee MDPI, Basel, Switzerland. This article is an open access article distributed under the terms and conditions of the Creative Commons Attribution (CC BY) license (http://creativecommons.org/licenses/by/4.0/). 